\title{
Extrametricality and second language acquisition
}

\author{
Guilherme Duarte Garcia \\ McGill University
}

\section{Introduction}

This pilot study investigates the second language acquisition (SLA) of stress in Portuguese (L2) by native speakers of English (L1). In particular, it examines the interaction between extrametricality and default stress through two judgement tasks. Stress is suprasegmental, relative and involves a variety of phonetic correlates: Cross-linguistically, stressed syllables tend to be realized with higher pitch, longer duration and greater intensity_but languages differ as to which of these correlates is more or less significant. Phonologically, stress presents some unique characteristics, such as the absence of a categorical feature [ \pm stress]. Languages may also differ as to whether syllable shape affects stress (weight-sensitive) or not (weight-insensitive). Second language learners (L2ers) have to deal with such variability and, more importantly, have to acquire new stress patterns - some of which are often vastly different (even contradictory) when compared to the patterns (and phonetic cues) in their L1.

Both English and Portuguese are weight-sensitive languages. In such languages, the segmental profile of syllables has an effect on where stress falls within a word. For example, in many languages a CVC syllable is heavier than a CV syllable, and is therefore more likely to attract stress. This is the case in Portuguese, where the locus of weight effects is traditionally argued to be the word-final syllable. Like Portuguese, English stress is also affected by weight. However, the locus of weight effects in English is most often the penult syllable (Hayes 1982) — final syllables are affected by weight in specific contexts (\$2).

The reason Portuguese and English treat word-final syllables differently is due to another aspect in which languages may differ, namely, extrametricality. In some languages, like English, the final syllable is skipped (i.e., it is extrametrical) when stress is assigned. Other languages, like Portuguese, do not skip final syllables. This is yet another difference that learners have to acquire.

These facts about stress are quite challenging to adult L2ers (Dresher \& Kaye 1990, Pater 1997, Özçelik 2013), whose ability to acquire a second language is more constrained when compared to children (Critical Period Hypothesis, Penfield \& Roberts (1959), Lenneberg et al. (1967), Singleton \& Lengyel (1995)). For example, adult L2ers' prosody may be accentuated by incorrect stress assignment, even though their L2 syntax may be native-like (White 2003) — this is one of the reasons why we can easily tell if a speaker is native only by paying attention to his or her prosodic patterns.

In this paper, I show that L2ers successfully manage to assign stress to word-final syllables and, at the same time, avoid stress on the antepenult syllable, thus contradicting their L1 grammar. The hypothesis entertained is based on the fact that by resetting extrametricality, penult stress naturally becomes a more natural site for primary stress_-given that Portuguese builds trochaic feet.

\section{English and Portuguese stress}

Both languages investigated in this paper are quantity-sensitive and have different stress systems for nouns and verbs: In Portuguese, stress is only phonologically determined in non-verbs-stress in verbs does not depend on weight. In English, on the other hand, stress in both verbs and nouns relies on phonological factors-but these two classes are affected in different ways (Hayes 1982, 1995). The focus of this paper will thus be stress in nouns, which are sensitive to weight in both Portuguese and English—albeit in different ways.

As we will see below $(\S 2.1, \S 2.2)$, the stress patterns in English and Portuguese are clearly different in at least two respects: Extrametricality (YES for English; No for Portuguese), as we saw above, and default

\footnotetext{
* Thanks to Heather Goad and Lydia White for important comments on this study.
} 
stress position (antepenult for English; penult for Portuguese).

2.1 English The basic characteristics of English stress have been known for decades (e.g., Chomsky \& Halle 1968, Liberman \& Prince 1977, Hayes 1982, Halle \& Vergnaud 1987), but scholars have proposed substantially different analyses (rule- and constraint-based) to account for the patterns in the language. There is also evidence that English stress is not actually derived, i.e., words in the lexicon already have metrical information (Selkirk 1980). In that case, English would be more similar to languages with free stress. Whether or not stress is in the lexicon, the influence of phonological factors such as weight is relatively uncontroversial, in that systematic patterns are clearly observable. For example, Liberman \& Prince (1977) note that words such as pódectal are not found in any English corpus and sound unnatural to native speakers. The fact that such forms violate the rules of foot construction show us that phonological factors are unquestionable in the productivity of English words vis-à-vis stress patterns.

Even though stress in both verbs and nouns is influenced by phonological factors, these two classes follow slightly different stress patterns: In nouns, stress falls on the penult (PU) ${ }^{1}$ syllable if that syllable is heavy, and on the antepenult (APU) syllable otherwise: Arizóna, veránda, agénda but América, Cánada, cápital - final (U) stress is generally avoided. ${ }^{2}$ In verbs, final stress is not avoided as long as a complex coda or VVC sequence is present word-finally: tòrmént vs. devélop vs. impróve. These are not categorical rules in the language, but rather strong tendencies.

Despite the distinct behaviour word-finally, Hayes (1982) proposes that verbs and nouns in English actually follow the same patterns, including extrametricality and weight-sensitivity. The difference, however, is what is extrametrical: The final syllable in nouns, and the final consonant in verbs: pré $\langle$ sent $\rangle(n)$ but presén $\langle t\rangle(v)$. Since the present study focuses solely on nouns, the directly relevant L1 pattern in question is word-final syllable extrametricality.

2.2 Portuguese In Portuguese, as in several other Romance languages, stress is constrained by a trisyllabic window, so no pre-antepenult stress is allowed. In verbs, stress is morphologically defined based on the number/person and mood/tense suffixes-no phonological factors are involved (Bisol 1994, Lee 2007, Wetzels 2007 and many others). Non-verbs (nouns and adjectives), however, are strongly affected by weight: Stress is generally final if the word-final syllable is heavy, and penult otherwise. Antepenult stress is considered idiosyncratic, and is mostly restricted to words of Greek/Latin origin (Collischonn 2007, Araújo et al. 2011).

In standard metrical accounts, Portuguese regular stress has been analysed with syllabic $(\sigma)$ and moraic $(\mu)$ trochees $^{3}$ (see Bisol (2010) for a review). Because words with regular final stress always contain a heavy final syllable, such words are footed as $\left[\sigma \sigma\left(\hat{\sigma}_{\mu \mu}\right)\right]$. Words with regular penult stress always have a light final syllable, and because non-final syllables are traditionally assumed to be weight-insensitive, such words are footed as $[\sigma(\delta \sigma)]$, regardless of syllabic structure.

Heavy syllables in Portuguese contain either a falling diphthong or a coda consonant. Possible codas are $/ \mathrm{R}, 1, \mathrm{~N}, \mathrm{~s} / .^{4}$ Codas clusters are rare, and are limited to /Cs/ in two contexts: (i) Word-finally, when the noun is pluralized (trem $\rightarrow$ trens 'train(s)' $n$ ), and (ii) word-internally, such as trans.por.te 'transport'. Thus, unlike English, codas are qualitatively and quantitatively very limited in Portuguese.

Irregular stress is divided into three categories: (i) Antepenult (APU) stress, (ii) penult (PU) stress when the final syllable is heavy (H), and (iii) final (U) stress when the final syllable is light (L). In Bisol's (2013) analysis, (i) and (ii) are accounted for by extrametricality. In words with antepenult stress (i), such as nítido 'sharp', the final syllable is extrametrical (indicated by $\langle\ldots\rangle)$ and a trochee is built (R-to-L): (níti) $\langle$ do $\rangle$. For

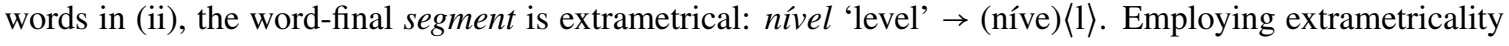
regularizes stress in (i) and (ii). This approach necessarily requires that a subset of the words in Portuguese be marked in the lexicon with exceptional extrametricality, since not all nouns or adjectives will contain

\footnotetext{
1 In this paper, I use the following conventions: Antepenult stress = APU; Penult stress = PU; Final stress = U.

2 Words with final stress typically end in a VVC syllable: políce, ballóon. As well, French borrowings tend to keep their French word-final stress.

3 Moraic trochees contain two moras (weight-bearing units), that is, either two light syllables or one heavy syllable. In contrast, a syllabic trochee contains two syllables, regardless of their weight.

$4 / \mathrm{R} /$ in codas can be realized as $[\mathrm{x}],[\mathrm{r}]$ or $[\mathrm{h}]$, depending on the dialect. /N/ is normally realized as $[\mathrm{g}]$ or $[\mathrm{p}]$ when preceded by a high front vowel.
} 
an extrametrical segment or syllable. It has also been proposed (Lee 2007) that antepenult stress is simply marked as such in the lexicon.

For words in (iii), such as café 'coffee' and maré 'tide', two solutions have been proposed: Bisol (1994) suggests that an abstract consonant is present word-finally (e.g., caféC). This catalectic consonant makes the word-final syllable heavy (i.e., it bears a mora). Some support for this analysis comes from derived forms, where the abstract consonant is phonetically realized: maré $+-i a \rightarrow$ maresía 'sea air'. However, the quality of the catalectic consonant may vary across different contexts, which casts doubt on the analysis: caféC + -al $\rightarrow$ cafezál 'coffee plantation'; caféC + -eria $\rightarrow$ cafetería 'cafeteria'. A second solution (Pereira 2000 and Lee 2007) assumes that the stress domain in Portuguese is in fact the derivational stem: Stress falls on the last vowel of the stem. For example, in café, the word-final vowel belongs to the stem, so stress is final. In a word like menin-o 'boy', however, the word-final vowel is a theme vowel (TV), and is therefore outside the stem. As a result, stress is penult in this case. The issue here is that stress and theme vowels are perfectly correlated, since such vowels are never stressed. In other words, we only know that the word-final vowel is not thematic if it is stressed (and vice-versa).

When examining lexical patterns, an important distinction needs to be made between syllabic shapes that favour stress and syllabic shapes that are more commonly attested. Based on Garcia (2014b), having a coda consonant in the penult syllable makes penult stress slightly more likely. On the other hand, among all words with penult stress in the lexicon, more than $70 \%$ have no coda in the penult syllable. These are two very different facts about the language: Significant effects on stress do not have to correlate with overall frequency in the lexicon. For Portuguese, they do not, as even though penult codas significantly affect penult stress, the majority of words with penult stress have no codas in that particular position. This distinction is essential for the discussion that follows, given the nature of the experimental design used in this study.

Table 1: English and Portuguese stress: Patterns in nouns

\begin{tabular}{rll}
\hline & English: $\sigma \sigma\langle\sigma\rangle$ & Portuguese lexicon: $\sigma \sigma \sigma$ \\
\hline Regular & Penult (if heavy) or antepenult & Final (if heavy) or penult \\
Irregular & Final & Antepenult \\
\hline
\end{tabular}

2.3 Weight effects and extrametricality Throughout this paper, I assume that L2ers' initial state is transferred from their L1 grammar, and that learners have access to language universals (Full Transfer Full Access Hypothesis (FTFA), White 1989, Schwartz \& Sprouse 1996). As a result, native English speakers are expected to transfer the stress patterns from English to Portuguese, at least initially, and later reset the necessary parameters to match the L2 grammar being acquired. However, the L2ers in the present study are not at their initial state (i.e., none of them are beginners), which means we may no longer observe explicit transference from English. Nevertheless, transference effects may persist as learners progress towards more advanced proficiency levels.

As we saw above, stress in word-final syllables is avoided in English nouns (due to extrametricality). Instead, stress falls on the penult syllable if it is heavy (antepenult stress otherwise). Therefore, English speakers are not expected to have problems with antepenult stress in Portuguese-even though this position is dispreferred in the L2. However, L2ers' behaviour regarding antepenult stress may change as they learn that final stress is common and not avoided in Portuguese, which requires learning that extrametricality does not play a role in the L2. For example, let us assume a word with three light syllables (LLL). L1 transference would lead L2ers to parse such a word as $(\sigma \sigma)\langle\sigma\rangle$. In other words, learners would skip the final syllable and build a trochee. As they learn that Portuguese final syllables are not extrametrical, they will parse our LLL word as $\sigma(\sigma \sigma)$. At this stage, they are expected to avoid antepenult stress. In other words, the expectation is that by resetting extrametricality, L2ers' default stress position in Portuguese will be target-like. 


\section{Methods}

The experiment developed for this pilot study involved a pre-test with real Portuguese words $(n=30)$, and two tasks involving pairwise comparisons of nonce words $(n=60)$. All participants also completed a questionnaire which asked several questions regarding their linguistic background as well as relevant personal information. Below I provide details on the tasks and the participants involved in this study.

All the stimuli in the experiment were presented orthographically. Because this paper is not focused on the phonetic cues to stress, auditory stimuli were not used. As a result, some influence of orthography is possible, even though the grapheme-phoneme correspondence in Portuguese is quite isomorphic, unlike English. This makes written Portuguese a fairly accurate tool for speakers and learners. As for stress, Portuguese orthography contains diacritics $\left({ }^{\prime},{ }^{\wedge}\right)$ to indicate irregularities. For example, all words with (i) penult stress ending in a heavy syllable or (ii) antepenult stress are orthographically accented: fácil, nível, ambito 'easy, level, scope'. For that reason, no diacritics were used in this experiment.

Most previous studies on the second language acquisition of stress (Pater 1997 and Tremblay 2007 for French and English; Özçelik 2013 for French, English and Turkish) involved either perception or production tasks. In such cases, the objective was to verify which phonetic cues L2ers used, or where they would produce stress in nonce words. The present study, however, made use of forced-judgement tasks.

As we saw in $\$ 2.2$, Portuguese stress is highly correlated with syllable shape. Consequently, given nonce words, native Portuguese speakers will almost always follow the regular patterns in the language (Hermans \& Wetzels 2012). This correlation observed in the Portuguese lexicon creates a confounding factor for production tasks: Because (word-final) coda and nucleus effects are much stronger than onset effects (Garcia 2014b), such tasks would not be appropriate to investigate other possible effects in the language. In fact, any target stress pattern that is not regular in the language is difficult to examine with a production task - this was also observed for L2ers in the pre-test ( $\$ 3.1$ below), which involved the production of isolated words and a paragraph: Learners generalized based on the regular patterns in the language.

The total duration of the experiment was approximately one hour, and participants were compensated for their time. All participants were tested at the Prosody Lab in the Linguistics Department at McGill.

3.1 Pre-test A core assumption of the experiment is that speakers are capable of (actively) locating the stressed syllable in different words. Also, it is important that speakers know that stress can only occur on the last three syllables of the word. Thus, the objective of the pre-test was to verify whether speakers could identify the stressed syllable of real words (nouns) in Portuguese $(n=30)$ - these words included all three possible stress positions in the language. Besides words with antepenult stress $(n=10)$, other irregular cases were included (such as ...Ĺ] and ...ĹH]). As a result, 18 out of the $30(60 \%)$ words had irregular stress. A secondary objective of the pre-test was to verify whether speakers were comfortable with the methodology used throughout the entire experiment.

All 30 words in the pre-test were relatively common nouns in spoken Portuguese, and L2ers were asked after the experiment whether they were familiar with the words-all non-native participants reported being familiar with at least 28 of the 30 words. The number of alternatives was proportional to the number of syllables in the word, so that words with four syllables also included an ungrammatical alternative in Portuguese, namely, words with pre-antepenult stress.

(1) Sample pre-test question ${ }^{5}$

fosforo

a. fosFOro

b. FOSforo

c. fosfoRO

As can be seen in (1), stress was indicated by capital letters (stressed syllable)—all orthographic accents were removed. Note, too, that grapheme-phoneme correspondence, as mentioned above, is fairly isomorphic in (1) - even though this was not an important assumption for the real words in the pre-test, it is essential for the rest of the experiment, where nonce words are used. Both natives and L2ers took the pre-test. L2ers'

5 Correct answer: b. IPA: /'fos.fo.ro/. 
accuracy was relatively high, ranging from 15 to 30 (out of 30), with a mean of 22.6-natives performed at ceiling. Both natives and L2ers seemed to be aware of the trisyllabic window: Of all tokens longer than three syllables ( $n=150$ ( 5 out of 30 per speaker)), only one was assigned pre-antepenult stress (this was an L2er's response).

After the pre-test, task questions were randomized. Thus, speakers were not aware of the different kinds of tasks present in the experiment. For all intents and purposes, speakers participated in a single task.

3.2 Tasks The format of the experiment tasks was slightly different from that of the pre-test. Firstly, only nonce words were used. All nonce words in tasks A and B were generated by a script developed in $\mathrm{R}^{6}$ (Garcia 2014c). ${ }^{7}$ Speakers were presented pairs of words, each of which labelled the end-points of a 7-point scale-all intermediate points had no labels. Participants were told that words were singular nouns, and were then asked to judge the naturalness of such words by using the scale. ${ }^{8}$ For tasks involving codas, all possible codas in Portuguese were used, namely, /r, $1, \mathrm{~N}, \mathrm{~s} /$. The same applied to onset clusters: All combinations allowed in the language were included. As for vowels, /a,e,i,o,u/ were varied so possible random effects could be analyzed later. Finally, possible OCP (Obligatory Contour Principle) effects were avoided by never including sequences of identical vowels or sequences of identical place of articulation for consonants.

3.2.1 Task A: Word-final codas As we saw in $\$ 2.2$, word-final codas are the most obvious cue for stress location in Portuguese. Task A aimed to confirm that natives actually use this particular cue. More importantly, it is not as obvious that L2ers whose first language is English would easily identify such a cue, given that word-final stress in English nouns is typically avoided due to extrametricality. In other words, the most obvious fact about Portuguese stress requires L2ers to make word-final syllables visible for stress assignment in nouns. In this task, speakers were shown words $(n=30)$ that contained a heavy final syllable: ...VC].

Task A involved pairs of structurally identical nonce words (i.e., identical segments, but different stress locations). Speakers were instructed to choose the word that would sound more natural in Portuguese if it existed. They were also explicitly told that there was no correct answer, and that the only thing being asked was their own impression/opinion as speakers (or L2ers) of Portuguese. All judgements ( $n=30$ ) were prefaced with the question 'Which of these two words sounds more natural?'

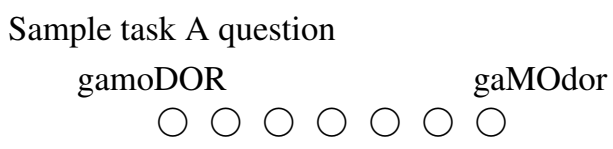

3.2.2 Task B: Word-internal codas Whereas task A aimed to confirm the clear effect of word-final codas in Portuguese, task B aimed to verify whether penult or antepenult codas also have an effect on stress. For example, given two distinct nonce words, one CV.CV́.CV and one CV.CV́C.CV, which one is more natural to speakers? If the effect of word-internal codas on stress is captured by speakers, then their judgements should mirror the statistical patterns found in the lexicon (Garcia 2014b), namely, a positive effect of penult codas on stress - even though most antepenult and penult syllables in the lexicon have no codas.

The structure of task B involved pairs of words: One word with a coda (in the antepenult or penult syllable), and one word with no codas. Therefore, two types of pairs were judged: (a) CV.CV́C.CV vs. CV.CV́.CV and (b) CV́C.CV.CV vs. CV́.CV.CV. All judgements $(n=60)$ involved the same 7-point scale from task A. By having the exact same stress position in both words, speakers' responses need to be based on structural differences.

Sample task B question

duFILma reSAdo

${ }^{6}$ R Core Team (2014).

7 All nonce words complied with Portuguese phonotactic rules. The stimuli were balanced for vowel/coda/onset quality.

8 Participants were instructed to interpret the mid-point as either uncertainty or neutrality. 
3.3 Participants Participants consisted of 20 native Portuguese speakers and 10 L2ers, all of whom lived in Montreal at the time of the experiment. Given the place of residence of the speakers, none of the native Portuguese speakers were monolinguals (English, French, Spanish and Italian were among the foreign languages spoken by these participants) - but all were Brazilian. All L2ers were native English speakers, and also spoke other foreign languages besides Portuguese. English native speakers who only speak/know Portuguese as a foreign language would be highly unlikely in Montreal, since most anglophones have at least some knowledge of French, for example. Also, given that Portuguese is rarely the first option for a second language, these limitations were unavoidable. All L2ers in the study reported that they learned Portuguese as adults.

Both natives and L2ers were relatively homogeneous: Almost all L2ers learned Brazilian Portuguese as opposed to European Portuguese $(n=9 / 10)$, and more than half of the natives came from the southern and southeastern regions in Brazil $(n=12 / 20)$. For L2ers who had some exposure to European Portuguese, this likely did not have an effect on the results, since stress in European and Brazilian Portuguese is identical. Likewise, different dialects in Brazil have no effect on the stress patterns in the language (Câmara 1970, Houaiss et al. 2001). The mean age was similar in both controls and L2ers $(\bar{x}=34.3, s=7.4$ and $\bar{x}=$ $31.9, s=12.2$, respectively). In the control group, 13/20 were females. Among the L2ers, $5 / 10$ were females.

As the present study needed to measure speakers' phonological knowledge, standard proficiency tasks (e.g., cloze tests) would not provide an adequate measure of proficiency. Crucially, participants had to be assessed in terms of their pronunciation (prosody, intonation and, naturally, stress). L2ers who do very well in writing or grammar tasks do not necessarily do well in an accent task, for example, as they may rarely speak the L2 they study.

For this study, the proficiency level of the L2ers was determined using a global accent rating task (see Akita (2001)). Before the experiment, each L2er read a paragraph containing 228 words in Portuguese. They were instructed to first read it carefully to themselves, and then read it out loud. The paragraph included words with stress in all possible positions, common and less common words, and regular as well as irregular stress patterns.

Each L2er was later rated by native speakers $(n=10)$ in Brazil and in Montreal. In addition to the 10 L2ers, four native speakers also recorded the same paragraph. The rating task therefore included paragraphs from 14 speakers-all randomized. To establish the upper and lower bounds in proficiency for the rating task, raters first listened to excerpts from the paragraphs of two speakers: one excerpt from the least proficient L2er in the sample (judged by the author and two other native speakers with linguistic training), and another from a native speaker. These were provided so that raters knew that all speakers in the sample should be rated relative to the two training excerpts. The excerpts contained the final 15 seconds of the paragraph mentioned above. The duration of the paragraph was approximately 2 minutes, but raters did not need to listen to the whole paragraph to judge the speaker's accent/proficiency. Ratings were based on a numbered 5-point scale. The endpoints were labelled as follows: $1=$ Least native-like; $5=$ Most native-like.

The mean score of each L2er was later correlated with their score in the pre-test (\$3.1). Raters had a relatively consistent agreement regarding speakers' accents $(\kappa=0.30, p=0){ }^{9}{ }^{9}$ Importantly, speakers' average rating was highly correlated with their accuracy in the pre-test $(r=0.78, p=0.007)$. Ratings ranged from 1.1 to 4.7 ( $\bar{x}=3.21, s=1.17$ ), which indicates that the sample was moderately heterogeneous (all four native speakers were rated at 5). Note that L2ers needed to be minimally proficient for this particular study, since we do not expect beginners to know enough about the phonological system of their L2 to judge acceptability of stress placement in nonce words. In the remainder of this paper, I will refer to three different rating bands, namely, Intermediate, Advanced, and Near-native. These are impressionistic labels, given that the ratings in question are assigned based on the sample of 10 L2ers in this study.

\section{Results and discussion}

Since the dependent variable in the data is a 7-point scale, I employ Ordinal Regression models, also known as Cumulative Link Models ( $\mathrm{clm}()$ in R). In such models, the response is not seen as continuous,

\footnotetext{
9 Fleiss's kappa test for reliability of agreement. Note that this test does not treat ratings as ordinal, and therefore $\kappa$ is lowered (i.e., agreement is underestimated) — there is no kappa test for ordinal data with more than two raters. A $\kappa$ value between 0.21 and 0.40 is considered 'fair' (Landis \& Koch 1977).
} 
Table 2: L2ers by mean accent rating (1-5)

\begin{tabular}{rrrrl}
\hline Band & Rating range & Mean rating & $\boldsymbol{n}($ L2ers) & \multicolumn{2}{l}{ Label } \\
\hline 1 & $1-3$ & 2.1 & 4 & Intermediate \\
2 & $3-4$ & 3.3 & 3 & Advanced \\
3 & $4-5$ & 4.6 & 3 & Near-native \\
\hline
\end{tabular}

and therefore only values from 1 to 7 are assumed in this case (see Agresti (2010) on Floor Effects and why Linear Regressions should not be used with ordinal data).

All the regressions presented in this paper model speakers' responses (1-7) based on a set of independent variables/predictors, e.g., proficiency level, L1, presence of a coda etc. The effect of each predictor $(\hat{\beta})$ may be positive or negative. Given the nature of the scale used here, a (significantly) positive effect $(\hat{\beta}>0)$ indicates that a predictor increases the likelihood of a higher rating, i.e., the right edge of the scale (7). Conversely, if $\hat{\beta}<0$ and $p<0.05$, a predictor increases the likelihood of a lower rating, i.e., the left edge of the scale (1).

Even though ordinal models are used throughout this section, I also report results from statistical tests. Because the data at hand are not normally distributed, these tests are non-parametric (Wilcoxon signed rank test with continuity correction). The non-normal distribution of the data will be clear in the violin plots (for that reason, no boxplots are used).

4.1 Task A: Word-final codas Word-final codas are the most salient factor regarding weight and stress in Portuguese, but transference from English predicts that L2ers will disprefer word-final stress even when the word-final syllable contains a coda consonant. As L2ers become more proficient, however, they should realize that final stress is considerably more likely than penult stress in such words. Natives, on the other hand, should have no problems applying this very robust pattern in the language to nonce words (\$2.2). In Fig. 1, we can see both L2ers' and natives' judgements regarding words with a heavy final syllable. Responses are based on a 7-point scale: ${ }^{10} 7$ indicates preference for penult stress, whereas 1 indicates preference for final stress-recall that all stimuli consisted of CV.CV.CVC words. As expected, native Portuguese speakers prefer nonce words with a heavy final syllable to bear final stress. This is the case for all but one group of words, namely, those with /s/ in coda position.

Taken as a single group, non-natives' patterns are very similar to natives' (results by proficiency are presented below). We can see that neither natives nor L2ers find penult stress unnatural in words with a heavy final syllable as long as the coda in that syllable is an /s/. Speakers might be treating /s/ differently because plural is marked by this particular phoneme in Portuguese, and since inflectional morphemes in the nominal domain do not affect stress in the language, morphological /s/ could be influencing judgements on any word-final /s/ - even though all participants were told the stimuli only included singular words. In the lexicon, only $3 \%$ of words with final stress end in an /s/ (the most common word-final coda in such cases is $/ \mathrm{R} /$ ), and of all /s/-final words in Portuguese, approximately $60 \%$ have final stress (Garcia 2014a). In Fig. 1, all other coda consonants clearly indicate that L2ers do not avoid word-final stress when the necessary conditions are met. Although the L2ers seem to be treating $/ \mathrm{m} /$ differently (median $=4$ ), there is no significant difference between $/ \mathrm{m} /$ and $/ \mathrm{l}, \mathrm{n}, \mathrm{r} /$ for L2ers taken as a whole $(p=0.09)$. Given the sample size, we should interpret this with caution. The fact that speakers seem to be less certain about $/ \mathrm{m} /$ is interesting in itself. As we will see below, this segment also behaves differently in other positions for learners as well as for native speakers.

Once we model the data using an Ordinal Regression, L1 is not a significant predictor of speakers' responses with regard to word-final codas $(\hat{\beta}=-0.01, S E=0.27, p=0.95)$. In other words, L2ers and natives are not significantly different overall—which is unsurprising, given the profile in Fig. 1. Furthermore,

\footnotetext{
${ }^{10}$ All plot titles indicate how the 7-point scale ( $y$-axis) should be interpreted.
} 
Figure 1: Speakers' responses by word-final codas: Natives $v s$. L2ers ( $y$-axis: $1=\mathrm{U} ; 7=\mathrm{PU})$. Nonce words with final codas $(/ \mathrm{l}, \mathrm{m}, \mathrm{n}, \mathrm{r} /)$ attract final stress in both groups. /s/ is treated differently (PU) by both natives and L2ers. Dotted line indicates the mid point (neutral) in the 7-point scale.

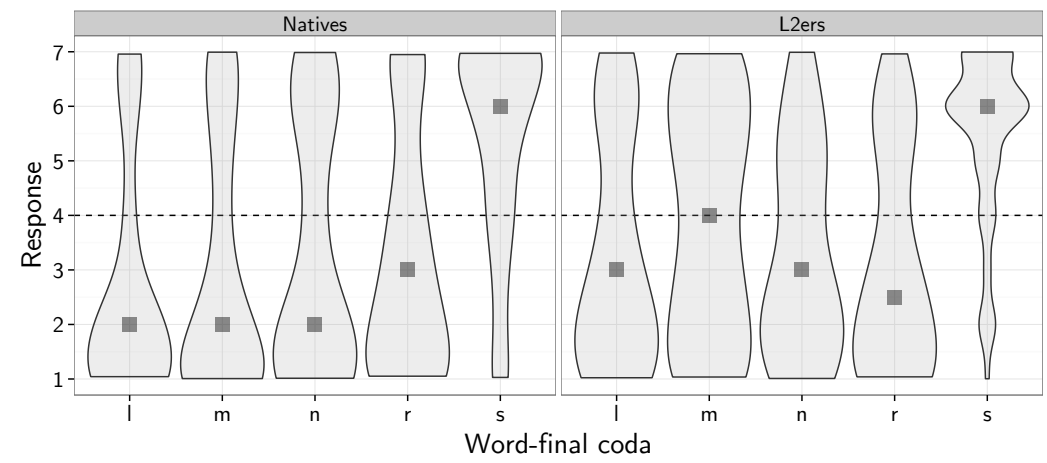

we find that a word-final /s/ in these data significantly increases the odds of penult stress $(\hat{\beta}=2.28, S E=$ $0.35, p<0.00001$ ) —in such a model, we predict the response (ordinal, 1-7) based on the L1 and the different possible word-final codas available in the data. A word ending in /s/ increases the odds of penult stress by a factor of $9.78(\exp (\hat{\beta}))$. The model in question also includes by-speaker random effects (final codas), which significantly improves the model's fit in a likelihood ratio test $(p<0.00001$, anova () in R).

Turning to the different proficiency levels among L2ers (Table 2), recall that the assumption here is that L2ers' initial state is the grammar transferred from their L1 (FTFA). However, none of these speakers were actually at the initial state, given that this experiment required at least some previous knowledge of Portuguese. Still, considering the three bands of proficiency presented in Table 2, can we say that there are important differences regarding word-final codas among L2ers? Fig. 2 separates final coda effects by proficiency level (from 1=Intermediate to $3=$ Near-native). Given the different behaviour observed for $/ \mathrm{s} /$ by all learners, only $/ 1, \mathrm{~N}, \mathrm{R} /$ are plotted. We can see that there is a clear trend downwards. That is, more proficient L2ers tend to prefer final stress on words that have a heavy final syllable-which is what we see in native speakers' responses. Responses from intermediate L2ers are clustered around 4, the mid-point, even though their median is slightly below 4 . Intermediate and advanced L2ers are not statistically different $(\hat{\beta}=$

Figure 2: Word-final codas across proficiency levels (1=U; 7=PU). Responses from L2ers rated as near-natives follow the same pattern observed in natives' responses.

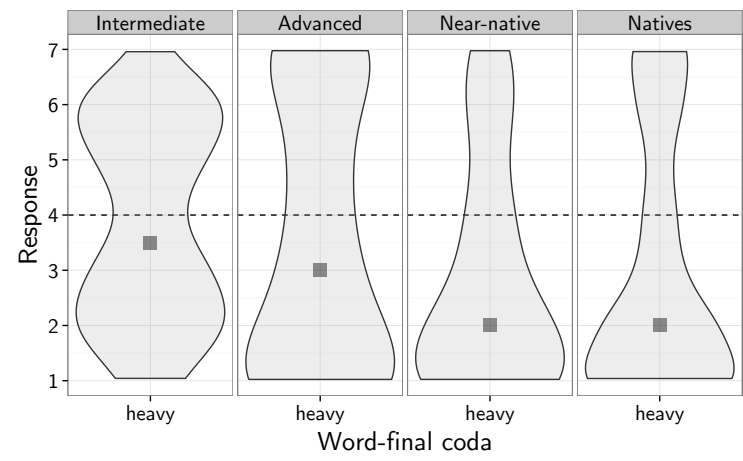

$-0.32, S E=0.28, p=0.26)$, but near-natives are significantly different from intermediates $(\hat{\beta}=-0.90, S E=$ $0.27, p=0.001$ ). That is, belonging to the near-native group has a significant effect on L2ers' responses. Taken as a whole, native English speakers' judgements of Portuguese nonce words are strikingly similar 
to those of native speakers, even though we can see a proficiency effect. In addition, the downward trend observed in Fig. 2 suggests that more basic learners still show some L1 effects, where word-final syllables are extrametrical in nouns.

Another trend is observed when we look at separate word-final coda consonants by proficiency level. In Fig. 3, we can see that intermediate L2ers' judgements are clustered around the neutral point in the scale (except for /s/, which already shows a very clear effect). If we now look at advanced L2ers' judgements, we can see that, except for $/ \mathrm{m} /$, responses are consistent with final stress in Portuguese, where word-final codas correlate with final stress. Finally, near-native L2ers mirror the same patterns observed for natives. In $\$ 4.2$, I explore possible explanations for the distinct behaviour of $/ \mathrm{m} /$, which is also observed in the antepenult coda position.

Figure 3: Word-final codas by consonant quality $(1=\mathrm{U} ; 7=\mathrm{PU})$

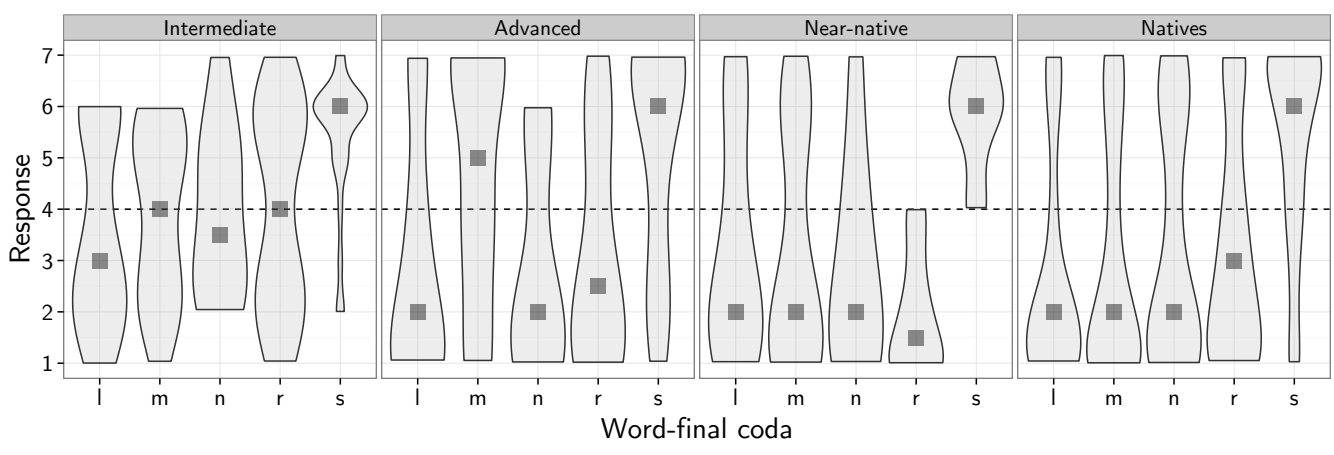

4.2 Task B: Word-internal codas Task B compared CV.CV́C.CV to CV.CV́.CV (PU), and CV́C.CV.CV to CV́.CV.CV (APU). Unlike word-final codas, word-internal codas have a much less clear effect on stress in Portuguese. Penult codas have at least an indirect effect: In words with antepenult stress, such codas are absent, clearly suggesting that some weight effect is present. Once we examine all Portuguese nouns and adjectives (Garcia 2014b), what we find is a highly significant effect of penult codas on stress-but such an effect is small (nearly four times smaller than the effect of word-final codas), which might explain why traditional analyses have missed it. Antepenult codas, however, show no significant effects in the lexicon. The question, thus, is whether these patterns match speakers' (and L2ers') judgements.

This task was designed to investigate whether the presence of a coda in the penult or antepenult syllable would affect speakers' judgements. A sensible trend to expect based on transference from English is that penult stress could be favoured when a coda consonant is present in the penult syllable ( 2.1$)$. Results for this task are shown in Fig. 4.

Figure 4: Penult and antepenult codas by L1 (1=CVC; 7=CV)

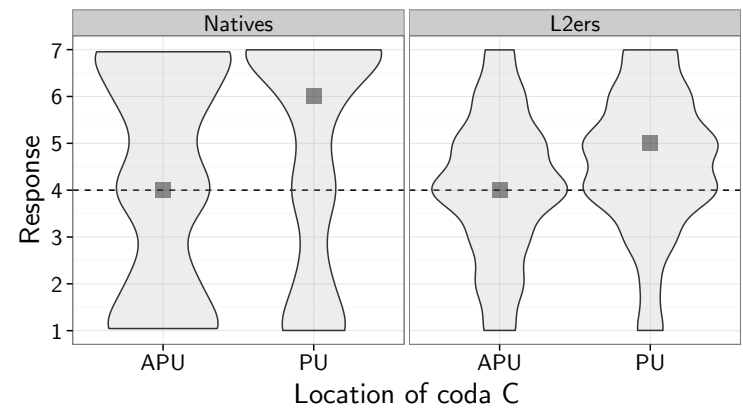

Here, higher response values indicate speakers prefer a stressed CV syllable to a stressed CVC syllable. 
The $x$-axis indicates which stress position is being judged - and therefore where the coda consonant is located. There are three important trends in Fig. 4: First, natives and L2ers show very similar patterns; second, both groups favour CV syllables over CVC syllables for penult stress. For antepenult stress, however, both groups show a neutral judgement. Third, L2ers' responses are more clustered around the neutral point when compared to natives, indicating less certainty.

As suggested by Fig. 4, natives and L2ers are not significantly different, that is, L1 does not have an effect on speakers' responses: $\hat{\beta}=-0.17, S E=0.18, p=0.32$. L2ers' judgements are particularly interesting, since a heavy penult syllable draws stress to this syllable in English nouns: If penult stress is the default in the L2, and that particular position happens to have a heavy syllable, one would assume that this is the ideal circumstance. However, that is not what we see: Coda location (PU) significantly affects speakers' responses overall $(\hat{\beta}=0.57, S E=0.21, p=0.005)$. This pattern is also observed if we model natives and L2ers separately. The results confirm the pattern in Fig. 4, i.e., penult CV syllables are preferred in nonce words with penult stress. In addition, natives' and L2ers' responses for PU are significantly different from the neutral position $\left(V=95554, p<0.00001 ; V=17648.5, p<0.00001\right.$, respectively). ${ }^{11}$

Natives, however, show more variation than L2ers, mainly for APU stress. In any case, it is surprising that both natives and L2ers follow the same pattern here: The trends observed differ from both English and the Portuguese lexicon, where stressed CVC syllables should be preferred in penult position, even though natives' judgements here are not inconsistent with the lexical patterns, as already noted, since most words in the lexicon have no codas.

Turning to coda segments, we saw in $\$ 4.1$ that /s/ behaved differently from all other coda consonants. One possible explanation was the fact that plural marker /s/, which never affects stress in Portuguese, could be influencing judgement of non-plural word-final /s/. If that is the case, then /s/ should not present distinct behaviour in positions where such influence is not possible, namely, word-internally. That is exactly what we find in the data: Fig. 5 shows no differences between /s/ and other coda consonants for the penult syllable (the same can be said for antepenult codas, see Fig. 6). That is, /s/ is only different word-finally. Elsewhere, its effect on speakers' judgements is not different from the effect of any other possible coda segment in Portuguese.

On the other hand, we see that $/ \mathrm{r} /$ has a very distinct behaviour among natives in Fig. 5. Natives seem to prefer penult $\mathrm{CV}$ syllables overall, except when $/ \mathrm{r}$ / is present in the coda position of those syllables. This effect is highly significant $(\hat{\beta}=-0.99, p<0.05)$, and cannot be explained by lexical patterns: Among all words with penult stress and a penult coda consonant, only $10 \%$ contain an $/ \mathrm{r} /$. The most common coda in these cases is $/ \mathrm{n} /(50 \%)$, and the least common is $/ \mathrm{m} /(3 \%)$. Among L2ers, coda quality had no effects.

Figure 5: Penult coda consonant by group $(1=\mathrm{CVC} ; 7=\mathrm{CV})$

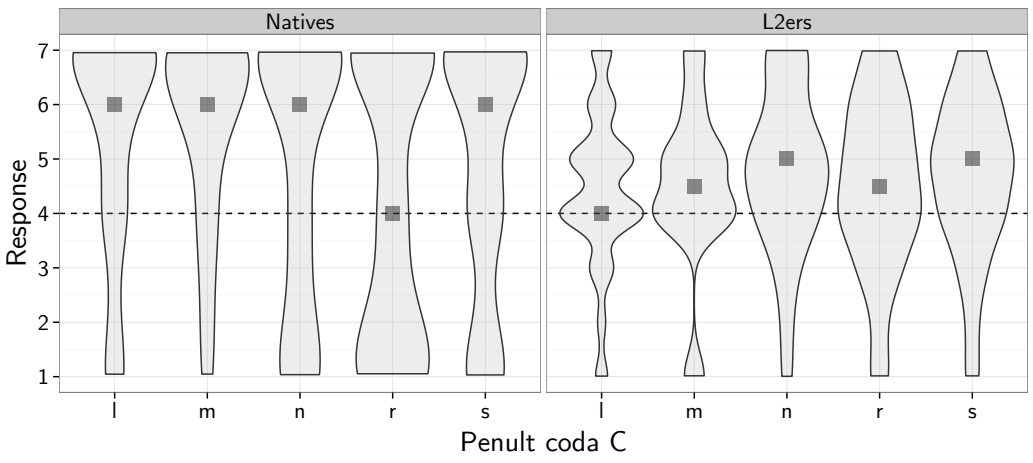

Even though natives and L2ers show similar trends in Fig. 5, L2ers' responses are clearly more uncertain, i.e., clustered around the mid point of the scale. This is an interesting difference here, which suggests a possible transference from the L1. Given that penult stress in English is highly correlated with a heavy penult syllable, learners may be more hesitant when judging nonce words in the L2, where most word-internal

\footnotetext{
${ }^{11}$ Wilcoxon signed rank test with continuity correction.
} 
syllables have no codas-in other words, the two languages have contradictory patterns in this particular position. This could explain why L2ers' responses are less similar to natives' in Fig. 5. Recall that weight effects in the penult syllable in Portuguese are much weaker when compared to word-final syllables. As a result, it is understandable that L2ers are less certain in this particular case.

As for antepenult position (Fig. 6), we can see that both natives and L2ers have very similar responsesboth are clustered around the mid point, which indicates no clear syllable preference for this position. Two important facts are relevant here: First, this is the most idiosyncratic position in Portuguese, where weight effects are much smaller and stress is less predictable in the first place. This could explain why natives are not certain as to which syllable shape they prefer. Second, unlike the penult syllable, antepenult syllables in English are not dependent on weight. That is, antepenult stress in English is the consequence of not having a heavy penult syllable. That being the case, L2ers have no reason to have a particular preference based on their L1. As well, the L2 they are exposed to offers virtually no evidence for coda effects in the antepenult syllable. Likewise, native speakers' responses show no evidence for antepenult coda effects, based on Fig. 6 .

Figure 6: Antepenult coda consonant by group $(1=\mathrm{CVC} ; 7=\mathrm{CV})$

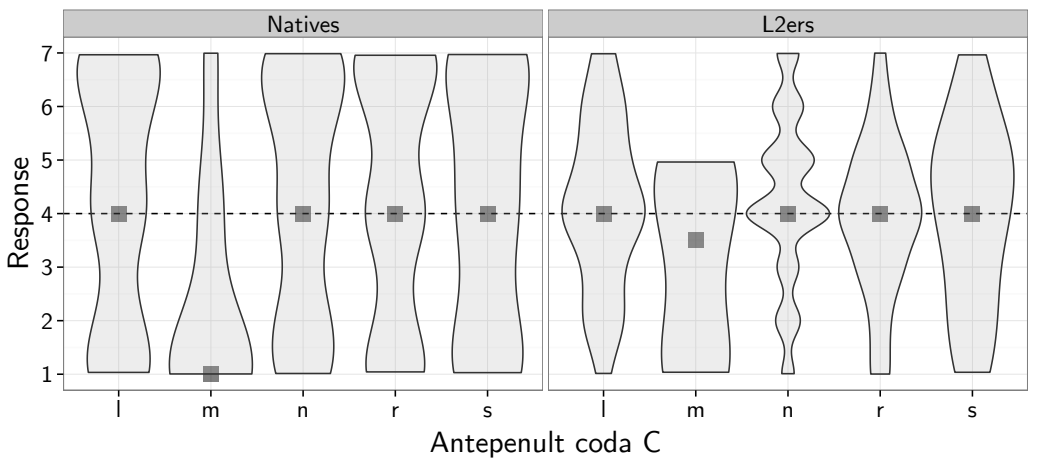

When we examine antepenult position and the different coda consonants there, we note an interesting pattern: $/ \mathrm{m} /$ is treated differently by both natives and L2ers (see Fig. 6) - recall that word-final $/ \mathrm{m} /$ is also treated differently by L2ers (Fig. 3). Among natives, speakers seem to judge all items as neutral except when $/ \mathrm{m} /$ is in coda position, in which case CV́m.CV.CV is clearly preferred to CV́.CV.CV-this effect is significant ( $\hat{\beta}=-1.94, p=0.04)$. That is, having an $/ \mathrm{m} /$ in the antepenult coda in a nonce word with antepenult stress increases the odds of speakers' preference for CVC. Among L2ers, these effects are not significant, but note that $/ \mathrm{m} /$ is the only segment with (i) a median below the neutral point and (ii) no responses at points 6 and 7 .

It is unlikely that the effects observed for $/ \mathrm{m} /$ here are due to lexical effects in Portuguese. Among words with antepenult stress and an antepenult coda, $/ \mathrm{m} /$ is the least frequent coda segment $(<5 \%)$. Thus, it is odd that speakers happen to prefer the least common segment as more natural. One could also wonder if nasality plays a role, but the behaviour of $/ \mathrm{n} /$ would be hard to account for-in addition, $/ \mathrm{n} /$ is three times more frequent in the Portuguese lexicon in this particular context. Being the only non-coronal coda consonant in Portuguese, place of articulation could be playing a role in this case. Since coronal codas tend to be preferred cross-linguistically, the fact that $/ \mathrm{m} /$ is more marked may explain why it stands out in Fig. 6 . This qualitative difference needs to be further examined.

4.3 Final remarks We have seen that L2ers successfully mirror native speakers in two situations: wordfinal weight effects and avoidance of APU stress. This suggests that L2ers adjusted extrametricality, and included word-final syllables into the stress domain. More importantly, L2ers also flipped the expected patterns for penult syllables, where preference for a heavy penult would not be ungrammatical in the L2, and would be consistent with the L1. Instead, speakers clearly favoured light penults, thus mirroring the exact same patterns we saw for natives. APU stress (default position in the L1) was deemed unnatural by L2ers, thus mirroring natives. These results are expected in a foot-based approach where the absence of extrametricality aligns parsing with the right edge of the word, thus creating a bias towards penult stress. 


\section{References}

Agresti, Alan (2010). Analysis of ordinal categorical data, vol. 656. New Jersey: John Wiley \& Sons.

Akita, Mamiko (2001). The phonological development of adult Japanese learners of English: a longitudinal study of perception and production. Ph.D. thesis, University of Durham.

Araújo, Gabriel Antunes, Zwinglio Oliveira Guimarães-Filho, Leonardo Oliveira \& Mário Eduardo Viaro (2011). Algumas observações sobre as proparoxítonas e o sistema acentual do português. Cadernos de Estudos Linguísticos $50: 1$.

Bisol, Leda (1994). The stress in Portuguese. Actas do Workshop sobre Fonologia. Universidade de Lisboa .

Bisol, Leda (2010). Introdução a estudos de fonologia do português brasileiro. Porto Alegre: EDIPUCRS, fifth edn.

Bisol, Leda (2013). O Acento: Duas Alternativas de Análise (Stress: two alternative analyses). Organon 28:54, $281-321$.

Câmara, Joaquim Mattoso (1970). Estrutura da língua portuguesa. Petrópolis: Editora Vozes.

Chomsky, N. \& M. Halle (1968). The sound pattern of English. New York: Harper \& Row.

Collischonn, Gisela (2007). Proeminência acentual e estrutura silábica: seus efeitos em fenômenos do português brasileiro. O acento em português: abordagens fonológicas. São Paulo: Parábola Editorial 195-223.

Dresher, B Elan \& Jonathan D Kaye (1990). A computational learning model for metrical phonology. Cognition 34:2, $137-195$.

Garcia, Guilherme D. (2014a). Portuguese Stress Corpus. Available at http : / /www . guil lherme. ca/psc.

Garcia, Guilherme D. (2014b). Weight gradience and stress in Portuguese. Under revision. Original submission available at http://ling.auf.net/lingbuzz/002332.

Garcia, Guilherme D. (2014c). Word Generator: An R script for generating pseudo-random words. GitHub repository available at https://github.com/guilhermegarcia/r/blob/master/word_generator.mo.

Halle, M. \& Jean-Roger Vergnaud (1987). An essay on stress. MIT Press, Cambridge, MA.

Hayes, Bruce (1982). Extrametricality and English stress. Linguistic Inquiry 227-276.

Hayes, B. (1995). Metrical Stress Theory: Principles and Case Studies. Chicago: University Of Chicago Press.

Hermans, Ben \& Leo Wetzels (2012). Productive and unproductive stress patterns in Brazilian Portuguese. Revista Letras 28.

Houaiss, Antônio, Mauro Villar \& Francisco Manoel de Mello Franco (2001). Dicionário eletrônico Houaiss da língua portuguesa. Rio de Janeiro: Objetiva.

Landis, J Richard \& Gary G Koch (1977). The measurement of observer agreement for categorical data. biometrics $159-174$.

Lee, Seung Hwa (2007). O acento primário no português: uma análise unificada na Teoria da Otimalidade. Araújo, Gabriel Antunes (ed.), O Acento em Português: abordagens fonológicas, São Paulo: Parábola Editorial, 120-143.

Lenneberg, Eric H, Noam Chomsky \& Otto Marx (1967). Biological foundations of language, vol. 68. New York: Wiley New York.

Liberman, Mark \& Alan Prince (1977). On stress and linguistic rhythm. Linguistic inquiry 8:2, 249-336.

Özçelik, Öner (2013). Representation and acquisition of stress: the case of Turkish. Ph.D. thesis, McGill University.

Pater, Joseph (1997). Metrical parameter missetting in second language acquisition. Language Aquisition and Language Disorders 16, 235-262.

Penfield, Wilder \& Lamar Roberts (1959). Speech and brain mechanisms. New Jersey: Princeton University Press.

Pereira, Maria Isabel Pires (2000). O acento de palavra em português: uma análise métrica. Ph.D. thesis, Universidade de Coimbra.

R Core Team (2014). R: A Language and Environment for Statistical Computing. R Foundation for Statistical Computing, Vienna, Austria, URL http: //www.R-project.org/.

Schwartz, Bonnie D \& Rex A Sprouse (1996). L2 cognitive states and the full transfer/full access model. Second language research $12: 1,40-72$.

Selkirk, Elisabeth O (1980). The role of prosodic categories in english word stress. Linguistic inquiry 563-605.

Singleton, David Michael \& Zsolt Lengyel (1995). The age factor in second language acquisition: A critical look at the critical period hypothesis. Bristol: Multilingual Matters.

Tremblay, Annie (2007). Bridging the gap between theoretical linguistics and psycholinguistics in L2 phonology: Acquisition and processing of word stress by French Canadian L2 learners of English. ProQuest.

Wetzels, W. Leo (2007). Primary word stress in Brazilian Portuguese and the weight parameter. Journal of Portuguese Linguistics 5, 9-58.

White, Lydia (1989). Universal grammar and second language acquisition, vol. 1. John Benjamins Publishing.

White, Lydia (2003). Second language acquisition and Universal Grammar. New York: Cambridge University Press. 